Article

\title{
Sequencing and Transcriptional Analysis of the Biosynthesis Gene Cluster of Abscisic Acid-Producing Botrytis cinerea
}

\section{Tao Gong ${ }^{1,2, \dagger}$, Dan Shu ${ }^{1, \dagger}$, Jie Yang ${ }^{1}$, Zhong-Tao Ding ${ }^{1}$ and Hong Tan ${ }^{1, *}$}

1 Key Laboratory of Environmental and Applied Microbiology, Chengdu Institute of Biology, Chinese Academy of Sciences, Chengdu 610041, China; E-Mails: gongtao2007@163.com (T.G.); whosecats@163.com (D.S.); abath@cib.ac.cn (J.Y.); dzhongtaochina@163.com (Z.-T.D.)

2 Henan Key Laboratory of Microbial Engineering, Institute of Biology, Henan Academy of Sciences, Zhengzhou 450008, China

$\dagger$ These authors contributed equally to this work.

* Author to whom correspondence should be addressed; E-Mail: tanhong@cib.ac.cn; Tel./Fax: +86-28-8289-0409.

External Editor: Lam-Son Phan Tran

Received: 26 May 2014; in revised form: 18 July 2014 / Accepted: 2 September 2014 / Published: 29 September 2014

\begin{abstract}
Botrytis cinerea is a model species with great importance as a pathogen of plants and has become used for biotechnological production of ABA. The ABA cluster of B. cinerea is composed of an open reading frame without significant similarities (bcaba3), followed by the genes (bcabal and bcaba2) encoding P450 monooxygenases and a gene probably coding for a short-chain dehydrogenase/reductase (bcaba4). In B. cinerea ATCC58025, targeted inactivation of the genes in the cluster suggested at least three genes responsible for the hydroxylation at carbon atom $C-1$ ' and C-4' or oxidation at C-4' of ABA. Our group has identified an ABA-overproducing strain, $B$. cinerea TB-3-H8. To differentiate TB-3-H8 from other $B$. cinerea strains with the functional ABA cluster, the DNA sequence of the $12.11-\mathrm{kb}$ region containing the cluster of $B$. cinerea TB-3-H8 was determined. Full-length cDNAs were also isolated for bcabal, bcaba2, bcaba3 and bcaba4 from B. cinerea TB-3-H8. Sequence comparison of the four genes and their flanking regions respectively derived from $B$. cinerea TB-3-H8, B05.10 and T4 revealed that major variations were located in intergenic sequences. In $B$. cinerea TB-3-H8, the expression profiles of the four function genes under ABA high-yield conditions were also analyzed by real-time PCR.
\end{abstract}


Keywords: Botrytis cinerea; abscisic acid; comparative sequence analysis; real-time PCR

\section{Introduction}

Abscisic acid (ABA) is a plant hormone that plays important roles in many aspects of plant growth and development and in the initiation of adaptive responses to various environmental conditions [1-3]. It is mainly produced by plants, but also produced by several species of filamentous fungi, such as the genera of Botrytis, Penicillium, Cercospora and Rhizoctonia, as a secondary metabolite [4,5]. Strains of $B$. cinerea have been shown to synthesize ABA; overproducing strains are used for biotechnological production of ABA [6-8].

Studies on the ABA biosynthetic pathway seem to be different in higher plants and fungi [9]. In higher plants, $\mathrm{ABA}$ is derived from the oxidative cleavage of $\mathrm{C}_{40}$ carotenoid. Carotenoids, like other isoprenoids, are synthesized from the $\mathrm{C}_{5}$ precursor, isopentenyl diphosphate (IPP), which is produced from the 1-deoxy-D-xylulose-5-phosphate (DXP) pathway. IPP is converted to $\mathrm{C}_{20}$ geranylgeranyl pyrophosphate (GGPP), from which $\mathrm{C}_{40}$ carotenoid was synthesized [10,11]. Most key genes of this pathway, such as genes for DXP synthase, GGPP synthase and carotenoid cleavage dioxygenase, were isolated and intensively studied with ABA-deficient mutants in many species, and the mechanism of this pathway has been well established [12].

In fungi, ${ }^{18} \mathrm{O}-,{ }^{2} \mathrm{H}$ - and ${ }^{13} \mathrm{C}$-labeling experiments were performed to study the ABA biosynthetic pathway of B. cinerea and several Cercospora species, and a pathway different from plants has been postulated: IPP, which is synthesized from the mevalonic acid (MVA) pathway, is converted to $\mathrm{C}_{15}$ compound farnesyldiphosphate (FPP). Additionally, after a series of reactions of cyclization, isomerization, desaturation and hydroxylation from FPP, ABA is synthesized [13,14]. However different species employ different biosynthetic intermediates. In C. cruenta, it has been accepted that ABA was synthesized via 1',4'-dihydroxy- $\gamma$-ionylideneacetic acid, while in B. cinerea and $C$. pinidensiflorae, 1',4'-trans-diol-ABA was detected as the main ABA intermediate, and in C. rosicola, 1'-deoxy-ABA was identified as a more important intermediate than 1',4'-trans-diol-ABA [15-18]. The difference in the biosynthetic pathway suggests that in fungi, the genes for ABA biosynthesis should be quite distinct from higher plants. However, the molecular mechanism driving ABA biosynthesis in fungi is still limited, and only a gene cluster containing four genes (bcabal, bcaba2, bcaba3 and bcaba4) in $B$. cinerea was revealed. In the non-sporulating ABA overproducer $B$. cinerea ATCC58025, targeted inactivation of the genes in the cluster suggested at least three genes responsible for the hydroxylation at carbon atom $\mathrm{C}-1$ ' and $\mathrm{C}-4$ ' or oxidation at $\mathrm{C}-4$ ' of $\mathrm{ABA}$, and PCR analysis showed that the organization of bcabal-4 is conserved in B. cinerea ATCC58025 and the highly pathogenic strain B05.10 [19,20]. In contrast to ATCC58025, strain B05.10 does not produce ABA in axenic culture. The mechanisms accounting for the yield diversity of ABA in $B$. cinerea remain enigmatic. Large-scale comparative sequence analysis provides important clues on conserved sequence features, such as genes and regulatory sequences [21]. With the recent progress in the genome analysis of several B. cinerea strains, greatly improved opportunities for comparative sequence analysis exist. Most notably, finished or draft sequences of the strains B05.10 [22] and T4 [23,24] genomes are available, giving us a chance to get 
important clues on conserved sequence features, such as genes and regulatory sequences by comparative sequence analysis $[25,26]$. Our previous study indicated a hyper-producer $B$. cinerea TB-3-H8 of ABA. The original $B$. cinerea was obtained from wheat stem and leaf and has been improved through a series of mutagenesis and screening over the years. Multiple rounds of mutagenesis and selection generated TB-3-H8 with an ABA productivity of $1.4 \mathrm{~g} / \mathrm{L}$ [27,28]. The maximum ABA yield of TB-3-H8 increased to $1.8 \mathrm{~g} / \mathrm{L}$ under optimized conditions. However, the molecular mechanisms behind the strain improvement for higher ABA production are poorly understood. In this study, the ABA biosynthetic gene cluster bcaba 1-4 of TB-3-H8 was sequenced. In addition, the expression levels of the four function genes during ABA production in $B$. cinerea TB-3-H8 have also been investigated. Comparative analysis of the biosynthetic gene clusters of $B$. cinerea strains TB-3-H8, B05.10 and T4 were performed to provide clues for molecular mechanisms of hyper-producing of ABA in TB-3-H8.

\section{Results}

\subsection{ABA Production of B. cinerea TB-3-H8}

B. cinerea TB-3-H8 was a mutant strain obtained after UV treatment of a wild strain originally isolated from wheat stem and leaf. Multiple rounds of mutagenesis and selection generated TB-3-H8 with an ABA productivity of $1.4 \mathrm{~g} / \mathrm{L}[27,28]$. The capability of TB-3-H8 to produce ABA was confirmed and quantified by HPLC analysis (Figure 1). Typical time-course profiles of ABA production and cell growth for fed-batch fermentation of TB-3-HB were also studied. Cell growth and ABA production of TB-3-HB in FJ2-FB2 medium with time are presented in later part of the section.

Figure 1. B. cinerea strain TB-3-H8. (a) Colonies formed by the B. cinerea TB-3-H8 on PDA plates 10 days after inoculation; (b) HPLC of 98\% $w / w$ ABA; (c) HPLC of ABA extracted from the culture medium.

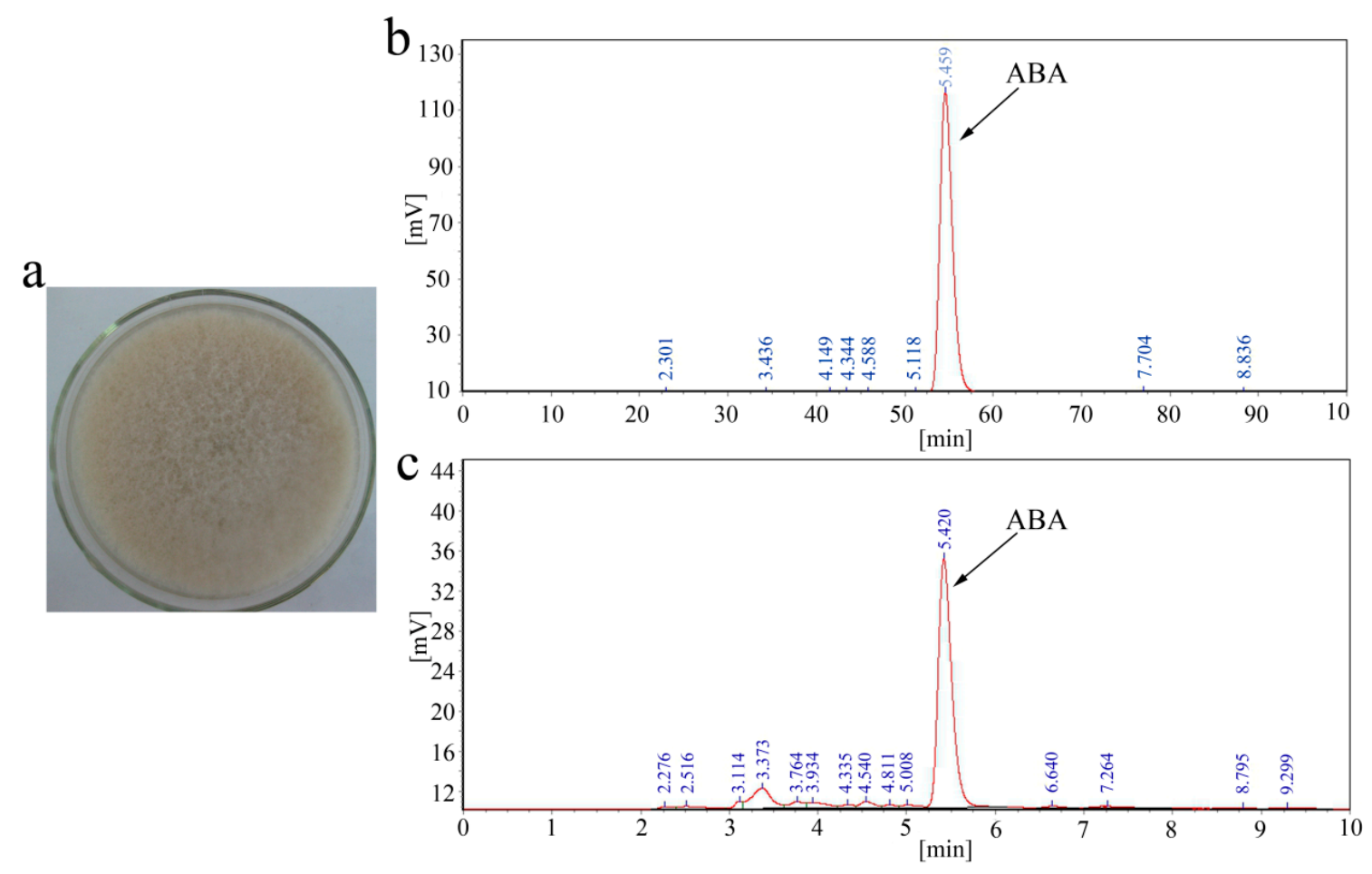




\subsection{Sequence Analysis of the ABA Cluster of B. cinerea TB-3-H8}

In view of the large amounts of ABA produced by TB-3-H8, we decided to check for the presence of the ABA gene cluster in the genomes of $B$. cinerea TB-3-H8. The gene cluster was first identified in $B$. cinerea ATCC58025, and targeted inactivation of the genes suggested that at least three genes are responsible for the hydroxylation at carbon atoms C-1' and C-4' or oxidation at C-4' of ABA.

To obtain the sequence of the ABA cluster, we performed several PCRs in strain TB-3-H8 with primers derived from the B05.10 genome (Figure 2). The fragment size of PCR products and sequence analysis revealed the same cluster organization for TB-3-H8 as that of B05.10 and T4 (Figure 3). The sequence homology of the intergenic noncoding regions between cluster genes from TB-3-H8 and B05.10 (or T4) was $73.7 \%$ (or $93.3 \%$ ) on average. Full-length cDNAs were also isolated for the bcabal, bcaba2, bcaba3 and bcaba4 from TB-3-H8 and compared with the homologous sequences in B05.10 and T4 (Table 1 and Figure 3).

bcaba3 is the first gene in the cluster. The full length of this sequence is $1323 \mathrm{bp}$, containing no introns. It showed that the translated protein had $88 \%$ and $99 \%$ amino acid identity with the products of the orthologous genes present in the ABA cluster of B05.10 and T4, respectively, and did not show any homology to known sequences as reported in strain ATCC58025. About 600 bps upstream of bcaba3, an RNA polIII-like promoter was detected.

bcaba1: The full length of this gene is 1769 bps. The five exons were interrupted by four introns, resulting in a protein containing 509 amino acids. The translated protein showed similarities to hypothetical protein P450 monooxygenase [29] and presented $87 \%$ and $100 \%$ amino acid identity to those of B05.10 and T4, respectively. About 450 bps upstream of bcabal, an RNA polIII-like promoter was also detected.

bcaba2: This 1810-bps gene, which contains four introns, showed similarity to several genes encoding P450 monooxygenases. Analyses of the deduced 527 amino acid sequence performed using the conserved domains database detected that the proteins contain the cypX multi-domains of the P450 superfamily [30]. The deduced protein of bcaba2 had $83 \%$ and $99 \%$ amino acid identity with those of B05.10 and T4, respectively. It should be noted that an alternative splicing in the second intron was detected in TB-3-H8 and T4, resulting in an amino acid deletion (Ala) between position 112 and 113 in TB-3-H8.

bcaba4: The last gene of the cluster encodes the short-chain dehydrogenase/reductase. It showed $98 \%$ and $100 \%$ identity with the deduced amino-acid sequence of B. cinerea B05.10 and T4, respectively.

Pairwise dot plot analyses revealed that all four sequences share a high degree of conserved synteny, and some rearrangements were observed (Figure 4). Interestingly, the 12,110-bps TB-3-H8 genomic sequence covered 19,278-bps of the B05.10 sequence. The homologous T4 genomic fragments (12,684-bps) were also smaller in size than the B05.10 sequence. The size difference between TB-3-H8 and the B05.10 genomic fragments is very pronounced as the B05.10 sequences carry a 10,863-bps insertion of two LTR retrotransposon elements between the bcabal gene and the bcaba3 ortholog (Figure 5). 
Figure 2. Primer pairs designed according to the sequence in the B. cinerea B05.10 genome.

\begin{tabular}{|c|c|c|c|c|}
\hline \multicolumn{5}{|c|}{ bcaba3 } \\
\hline (5) & 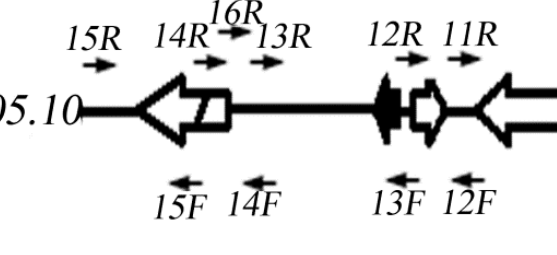 & 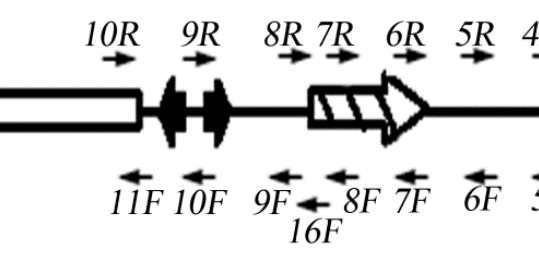 & 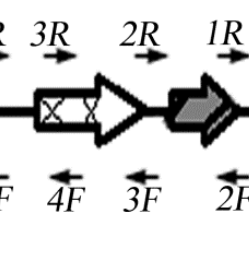 & $\overleftrightarrow{1 F}$ \\
\hline \multirow[b]{2}{*}{ Primers } & \multirow[b]{2}{*}{ Forward (5'-3') } & \multirow[b]{2}{*}{ Reverse (5'-3') } & \multicolumn{2}{|c|}{ Sequence Length (bp) } \\
\hline & & & $\begin{array}{c}\text { In B05.10 } \\
\text { Supercontig } 41 \\
\end{array}$ & $\begin{array}{c}\text { In TB-3-H8 } \\
\text { Genome }\end{array}$ \\
\hline 1 & GAGACGGAGAAGCTAAGGAGG & CATGATGGCAATACACCAGTT & $\begin{array}{c}1046 \\
(71,207-72,252)\end{array}$ & 897 \\
\hline 2 & CCATTTGGTTTGAGCTGCTTTG & СCTCCTTAGCTTCTCCGTCTC & $\begin{array}{c}1193 \\
(72,232-73,424)\end{array}$ & 1193 \\
\hline 3 & AATTATGCGAAGTCATGTCGA & ACTACCAAAGCAGCTCAAACC & $\begin{array}{c}1240 \\
(73,398-74,637)\end{array}$ & 1240 \\
\hline 4 & GGGTTTCACTGCGGAGTCTTG & GACTGATCCCATGCGGCAGAT & $\begin{array}{c}1221 \\
(74,359-75,579)\end{array}$ & 1221 \\
\hline 5 & ACTGTAGCCGAGATAGTAGGG & AGGCTTACGATTGGGCTGGAA & $\begin{array}{c}1371 \\
(75,467-76,837)\end{array}$ & 1386 \\
\hline 6 & AATGTGGAACTTGCCTTTGGT & CGTTACAACCCTACTATCTCG & $\begin{array}{c}933 \\
(76,809-77,741)\end{array}$ & 933 \\
\hline 7 & TCGATTCAATCCATATTATGACAAC & AAGTTCCACATTGCGCTCCATCTC & $\begin{array}{c}1177 \\
(77,730-78,906)\end{array}$ & 1177 \\
\hline 8 & CATAATGTGGGCTAACTACTCTGA & ACCGACCTCCAAGTCAGGCATAT & $\begin{array}{c}1034 \\
(78,786-79,819)\end{array}$ & 1034 \\
\hline 9 & ATTCGTCTGTGCGTAACCGTGCA & TCAGGTGGTGACGAATACAAGAT & $\begin{array}{c}1554 \\
(79,689-81,242)\end{array}$ & No data \\
\hline 10 & GCAGAAAGGGTGCTCAAAGTGTT & TGCACGGTTACGCACAGACGAAT & $\begin{array}{c}986 \\
(81,220-82,205)\end{array}$ & No data \\
\hline 11 & TTCCTGTGGTCGAGTTTATTG & AACACTTTGAGCACCCTTTCT & $\begin{array}{c}4500 \\
(82,183-866,682)\end{array}$ & No data \\
\hline 12 & TCAGTATGCCTCCTACACGAACA & GCAGCGTACTACAATACGAAACGT & $\begin{array}{c}1005 \\
(86,564-87,568)\end{array}$ & No data \\
\hline 13 & AGGCGGTTCCCTCTTAC & ACGGATACACTCGGCACAACG & $\begin{array}{c}2299 \\
(87,402-89,700)\end{array}$ & No data \\
\hline 14 & ACGATGTTTGTAGAAAGCCACTG & ATCCTCAAGAGTCGCAGTTCATA & $\begin{array}{c}1226 \\
(89,625-90,850)\end{array}$ & 1226 \\
\hline 15 & CGTCGCTGGGACAACATGCTCAA & AAGGCGAGTGAAAGACGAGATGG & $\begin{array}{c}1303 \\
(90,617-91,919)\end{array}$ & 1303 \\
\hline 16 & CGCAATGTCAGGAGGGTAGTA & TTATCGCAGAGAATCAGGCAG & $\begin{array}{c}10,943 \\
(79,374-90,316)\end{array}$ & 3762 \\
\hline
\end{tabular}


Figure 3. Structure of the ABA gene cluster (bcaba1, bcaba2, bcaba3 and bcaba4) and שmm comparison of SNPs among three strains. Sites in TB-3-H8 were used for standard positions of SNPs. Structure of genes in B05.10; — - Structure of gene inTB-3-H8 and T4; Structure of genes in B05.10, TB-3-H8 and T4, _ introns, _. - - intergenic sequences.

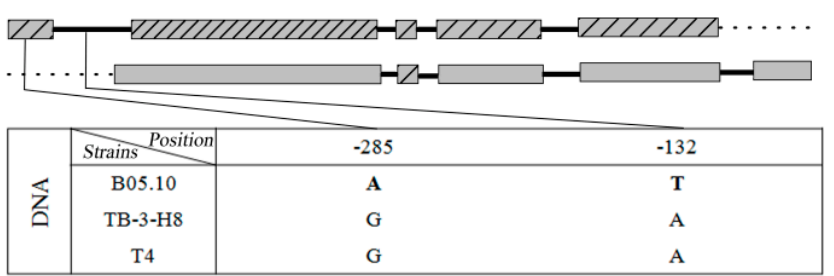

\begin{tabular}{|c|c|c|c|}
\hline . & Strains Position & I & I \\
\hline 6 & B05.10 & $\mathbf{v}$ & I \\
\hline$E$ & TB-3-H8 & I & I \\
\hline & $\mathrm{T} 4$ & I & I \\
\hline
\end{tabular}

\section{bcabal}

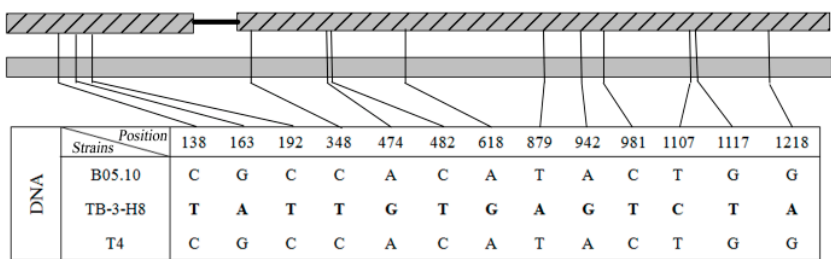

\begin{tabular}{|c|c|c|c|c|c|c|c|c|c|c|c|c|c|c|}
\hline \multirow{4}{*}{ 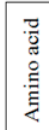 } & $\overbrace{\text { Strains }}$ Position & 46 & 55 & 64 & 116 & 158 & 161 & 206 & 293 & 314 & 327 & 369 & 373 & 406 \\
\hline & B05.10 & I & A & D & I & $\mathrm{K}$ & A & A & A & $\mathrm{R}$ & $\mathrm{T}$ & F & A & L \\
\hline & TB-3-H8 & I & $\mathbf{T}$ & D & I & $\mathrm{K}$ & $\mathbf{v}$ & A & A & $\mathrm{R}$ & $\mathrm{T}$ & F & s & L \\
\hline & $\mathrm{T} 4$ & I & A & D & I & $\mathrm{K}$ & A & A & A & $\mathrm{R}$ & $\mathrm{T}$ & F & A & L \\
\hline
\end{tabular}

bcaba3

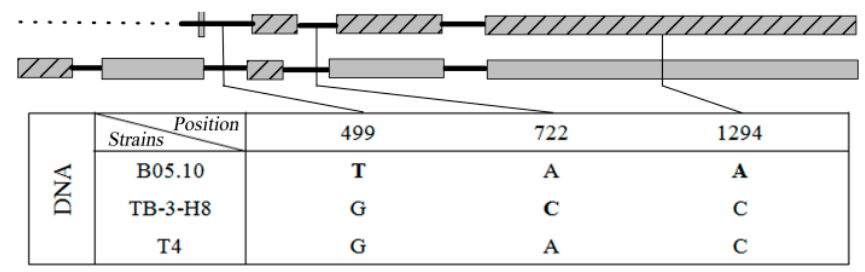

\begin{tabular}{|c|c|c|c|c|}
\hline$\frac{\pi}{0}$ & Strains Position & 1 & 186 & 356 \\
\hline శ్ & B05.10 & I & $\mathrm{R}$ & $\mathrm{S}$ \\
\hline$\Xi$ & TB-3-H8 & I & $\mathrm{R}$ & $\mathrm{S}$ \\
\hline$z$ & $\mathrm{~T} 4$ & I & $\mathrm{R}$ & $\mathrm{S}$ \\
\hline
\end{tabular}

bcaba2

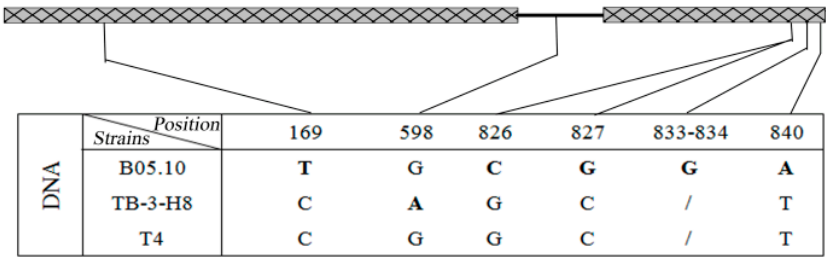

\begin{tabular}{|c|c|c|c|c|c|c|c|}
\hline 궁 & Strains Position & 53 & 1 & 253 & 254 & 257 & 258 \\
\hline 0 & B05.10 & $\mathrm{Y}$ & I & D & A & $\mathbf{E}$ & M \\
\hline$=$ & TB-3-H8 & $\mathrm{H}$ & I & D & G & $\mathrm{R}$ & C \\
\hline & $\mathrm{T} 4$ & $\mathrm{H}$ & I & D & G & $\mathrm{R}$ & C \\
\hline
\end{tabular}

bcaba4

Table 1. bcabal-4 genes identified in B. cinerea.

\begin{tabular}{cccccccc}
\hline $\begin{array}{c}\text { Gene } \\
\text { Name }\end{array}$ & $\begin{array}{c}\text { Strains } \\
\text { Names }\end{array}$ & $\begin{array}{c}\text { GenBank } \\
\text { Accession No. }\end{array}$ & $\begin{array}{c}\text { DNA } \\
\text { Length (bp) }\end{array}$ & $\begin{array}{c}\text { cDNA } \\
\text { Length (bp) }\end{array}$ & $\begin{array}{c}\text { Protein Size } \\
\text { (Amino Acids) }\end{array}$ & $\begin{array}{c}\text { No. of } \\
\text { Exons }\end{array}$ & $\begin{array}{c}\text { No. of } \\
\text { Introns }\end{array}$ \\
\hline \multirow{3}{*}{ bcabal } & TB-3-H8 & $/$ & 1769 & 1530 & 509 & 5 & 4 \\
& B05.10 & XM_001553921 & 1925 & 1482 & 493 & 5 & 4 \\
& T4 & FQ790338.1 & 1769 & 1530 & 509 & 5 & 4 \\
\hline \multirow{5}{*}{ bcaba2 2} & TB-3-H8 & $/$ & 1810 & 1584 & 527 & 5 & 4 \\
& B05.10 & XM_001553920 & 1507 & 1332 & 443 & 4 & 3 \\
& T4 & FQ790338.1 & 1810 & 1587 & 528 & 5 & 4 \\
\hline \multirow{3}{*}{ caba3 3} & TB-3-H8 & $/$ & 1323 & 1323 & 440 & 1 & 0 \\
& B05.10 & XM_001553924 & 1323 & 1269 & 422 & 2 & 1 \\
& T4 & FQ790338.1 & 1323 & 1323 & 440 & 1 & 0 \\
\hline \multirow{5}{*}{ bcaba4 4} & TB-3-H8 & $/$ & 842 & 777 & 258 & 2 & 1 \\
& B05.10 & XM_001553919 & 842 & 777 & 258 & 2 & 1 \\
\hline
\end{tabular}


Figure 4. Comparative dot plot analysis of the ABA cluster in B. cinerea B05.10 (A) and T4 (B) with respect to the TB-3-H8 strain.
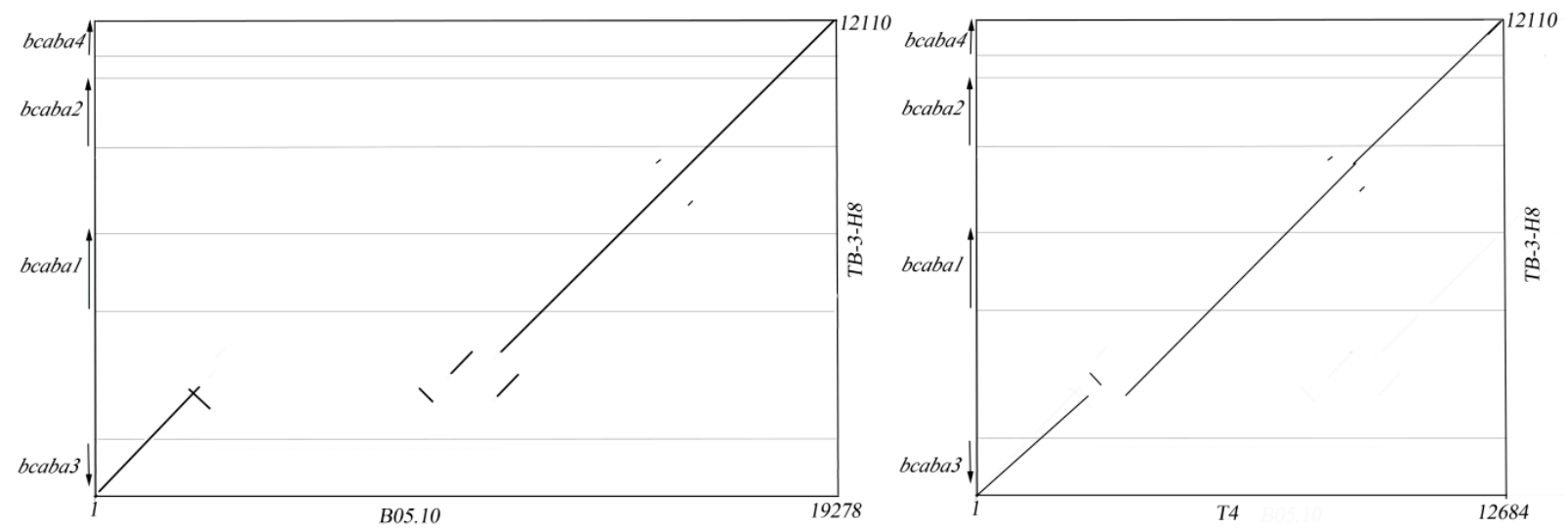

Figure 5. The structure of the ABA gene cluster in B. cinerea B05.10, T4 and TB-3-H8.
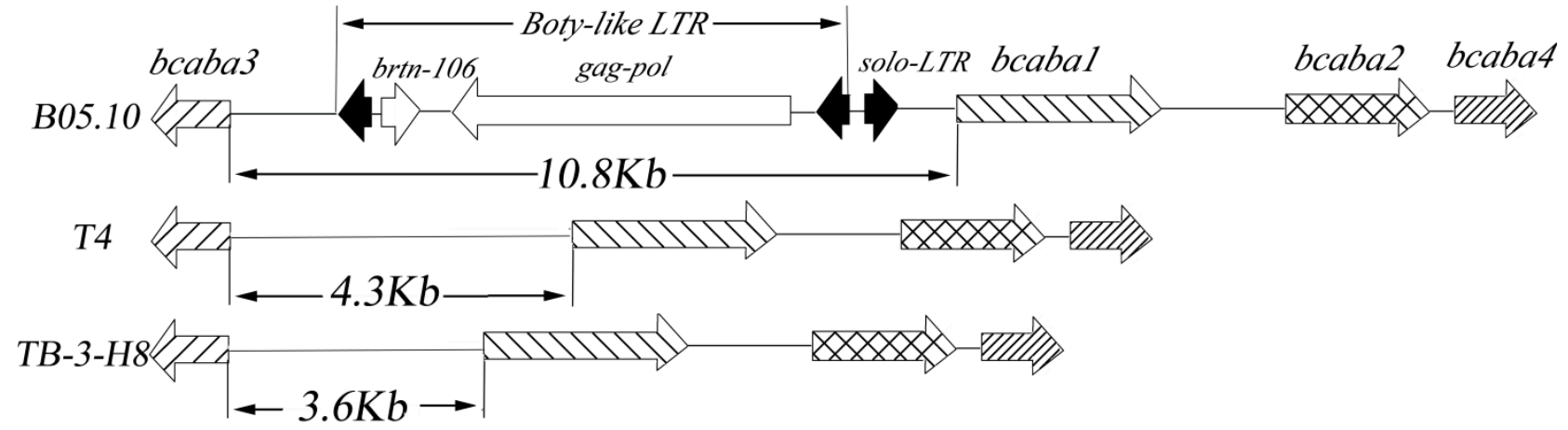

The sequence of this band revealed the presence of a solo LTR flanked by 5-bp "CTCAT" target site duplications (TSDs) and a gene encoding a Boty-like retrotransposons (Boty-like LTR) that cannot be found entirely in the corresponding region in B. cinerea TB-3-H8 and T4. The Boty-like LTR elements contained two identical LTRs and an internal gag-pol gene with brtn-106 [31]. The gene gag-pol encodes a protein with gag, ZnF_C2HC, RP, RT, IN and CHROMO domains that is potentially functional. The sequence of solo LTR is the same as that of the $5^{\prime}$ LTR of the Boty-like LTR, but orientated in the opposite direction (Figure 5).

A deeper look into the genomic information and the surrounding sequences was also undertaken for the genomes of TB-3-H8. Upstream of bcaba3, another putative open reading frame shows similarity to a ferulic acid esterase-encoding gene of Neurospora crassa as bcorf2. The right border of the sequenced DNA region showed similarity to fungal pectin lyase A precursor gene as $b c p l l$. It can be concluded that the organization of the genes from bcorf 2 to bcpll is conserved in B. cinerea strains TB-3-H8, B05.10 and T4. This is consistent with the result of Siewers et al. mentioned in 2006 [19].

\subsection{Transcriptional Analysis of the bcaba Cluster}

Real-time PCR was used to study the expression profiles of four genes. RNA isolated from B. cinerea TB-3-H8 cells grown in FJ2-FB2 medium was used for real-time PCR analysis. 18S rRNA was used as the internal control for this assay. The expression level was quantified according to the $2^{-\Delta \Delta C t}$ method. The expression level at $27 \mathrm{~h}$ of fermentation was used as a reference and was quantified as 1.0. As 
displayed in Figure 6, all four genes showed the lowest expression at $27 \mathrm{~h}$, belonging to exponential phase of growth, while each gene expression level increased when ABA began to be produced. The transcript level of bcabal and 2 reached the first peak at $52 \mathrm{~h}$, then decreased and peaked again at $113 \mathrm{~h}$. The transcript level of bcaba3 increased at $52 \mathrm{~h}$, then decreased until $113 \mathrm{~h}$ and peaked again at $137 \mathrm{~h}$. The expression of bcaba4 appeared to rapidly increase at $89 \mathrm{~h}$, then decreased and reached maximum expression at $161 \mathrm{~h}$.

Figure 6. Expression profiles of bcabal, bcaba2, bcaba3 and bcaba4 in B. cinerea TB-3-H8. - - cell weight, - - - ABA production, - - - relative expression level of bcaba1, bcaba2, bcaba3 and bcaba4, respectively.
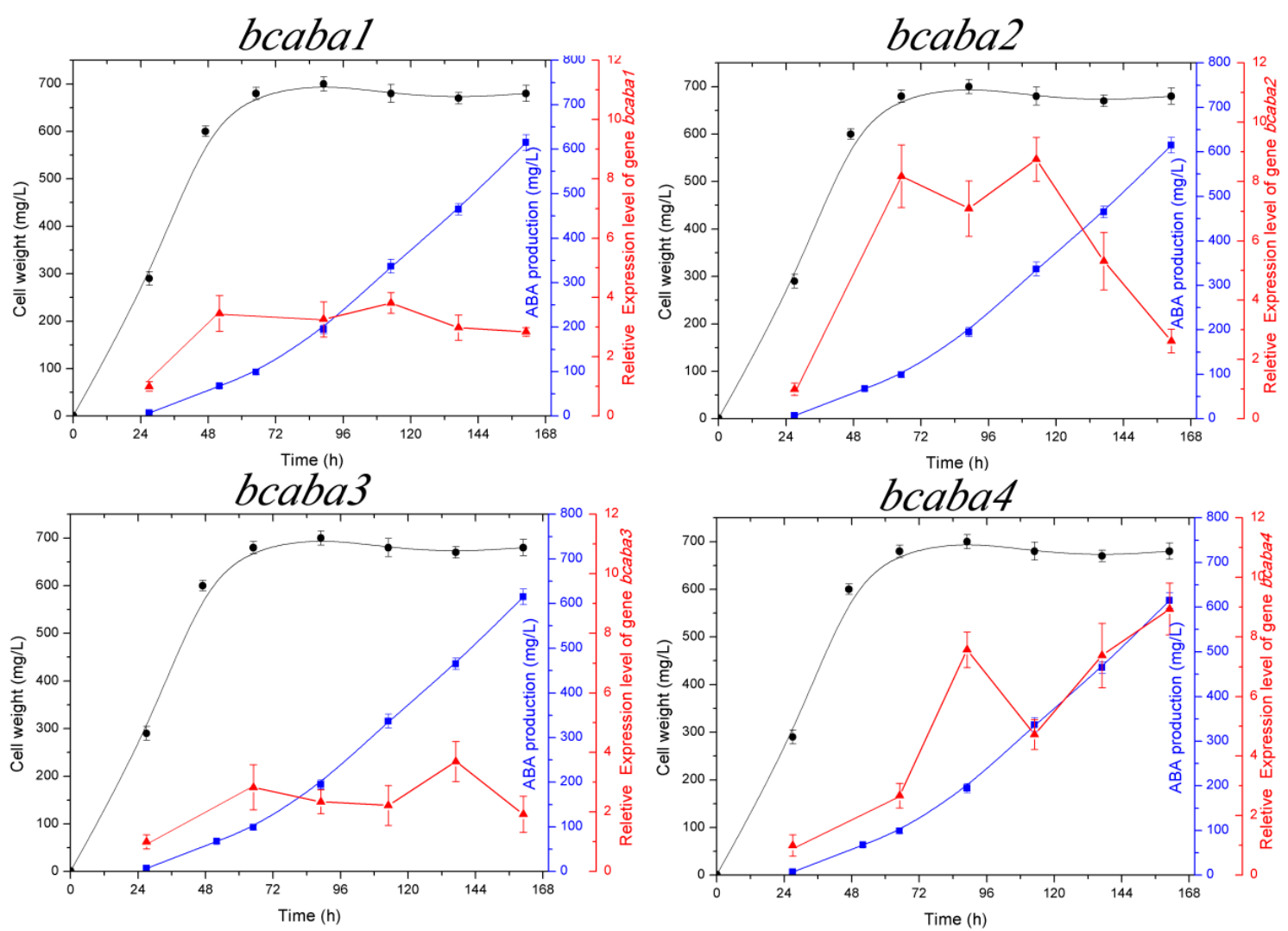

\section{Discussions}

B. cinerea are known as a typical necrotroph, which is responsible for the gray mold disease on more than 200 host plants and have been shown to synthesize ABA [32]. For industrial production of ABA, fermentative conditions using the fungus $B$. cinerea were examined. Irradiation with blue light stimulated the accumulation up to $5.5 \mathrm{mg} / 100 \mathrm{~mL}$ of potato-dextrose agar medium [33]. The microbial synthesis of ABA resulting in the accumulation up to $370.0 \mathrm{mg} / \mathrm{g}$ was reported for $B$. cinerea [34]. Strain ATCC 58025 of $B$. cinerea is a non-sporulating ABA overproducer, and a gene cluster containing four genes (bcaba1, bcaba2, bcaba3 and bcaba4) in ATCC58025 was revealed. Targeted inactivation of the genes in the cluster suggested at least three genes responsible for the hydroxylation at carbon atom C-1' and C-4' or oxidation at C-4' of ABA, and PCR analysis showed that the organization of bcabal-4 is conserved in ATCC58025 and the highly pathogenic strain B05.10, which do not produce ABA in axenic culture [19]. 
Our previous study indicated a hyper-producer $B$. cinerea TB-3-H8 with an ABA productivity of $1.4 \mathrm{~g} / \mathrm{L}$. In this report, we test the time-course profiles of ABA production and cell growth for fed-batch fermentation of TB-3-HB and found that strains B05.10 and T4 do not produce ABA under our condition (data not published) [35]. A detailed analysis of the ABA cluster bcabal-4 in strains TB-3-H8, B05.10 and T4 was also conducted. In some respects, all three clusters look very similar. The genetic organization of the sequenced genes bcabal-4 is the same in TB-3-H8, B05.10 and T4. Moreover, the surrounding regions of the ABA cluster are very well conserved in all of the analyzed strains. Two common genes (bcorf2 and bcpll) were located in all of the available $B$. cinerea genomes that comprise the ABA cluster. The bcorf 2 gene was located upstream in all of the analyzed strains. The downstream region of the ABA cluster is also well conserved.

In contrast to these similarities, all three clusters also exhibit significant differences. The coding regions of the ABA cluster in TB-3-H8 were more similar to that of the T4 strain ( $\geq 99 \%$ amino acid identity), but considerably different from that of B05.10. Only bcaba3 of TB-3-H8 contains three amino acid substitutions at positions 55, 161, 373 and an amino acid deletion in bcaba2 compared to T4. In recent studies, it has been shown that even single amino acid substitutions can be crucial for the functionality of the entire enzyme. Malonek et al. previously found that the loss of the ability to produce gibberellins resulted from several point mutations in the coding sequence and promoter regions of certain gibberellin biosynthetic genes [36]. Whether the several point mutations in the coding sequence of bcaba 3 are crucial for the functionality of the entire enzyme has to be elucidated.

Sequence comparison of TB-3-H8 and B05.10 or T4 genes revealed significantly more differences in the intergenic regions than in the coding regions. The distance between the bcabal and the bcaba3 gene differs among the genomes of the three strains. The intergenic region between the bcabal and the bcaba3 gene was also more similar to that of the T4 strain, but different from that of B05.10. Blast analysis showed that the $10,863 \mathrm{bps}$ in B05.10 were homologues to two LTR retrotransposon elements, which were not detected in the strain of TB-3-H8. It is reported that B05.10 shows low expression of bcabal and bcaba2 under the same conditions in which ATCC 58025 produces ABA. We also found that the levels of bcabal-4 in B05.10 and T4 are too low to be detected under the same conditions in which TB-3-H8 produces large amounts of ABA (data not published) [37]. This may be explained by the fact that the presence of the LTR element impeded the transcription of the bcabal or bcaba 3 and other genes, and resulted in an inability to produce ABA. Victor et al. previously investigated the biosynthesis gene cluster of putrescine-producing Lactococcus lactis [38]. They showed that, in some L. lactis subsp. lactis strains, the biosynthesis cluster are silenced by the occurrence of one or two IS elements. These examples once again demonstrate the flexibility of nature to achieve differences and similarities via various mechanisms and will surely inspire laboratory efforts to investigate the gene products of the $B$. cinerea ABA cluster. Whether the gene products of the $B$. cinerea ABA cluster in TB-3-H8, B05.10 and T4 are still functional has to be elucidated by further investigations.

In this report, we also investigated the expression levels of the four function genes during ABA production in TB-3-H8. Coregulation is a common feature of fungal metabolic pathway genes. However, it has been shown previously that the four putative ABA genes are not strictly coregulated in ATCC58025 [17]. The expression profile of bcabal shows a persistent induction 90 min after the addition of the ABA precursor, mevalonic acid (MVA), to the medium. A persistent induction could also be detected for bcaba2, starting, in contrast to bcabal, after $60 \mathrm{~min}$. Expression of bcaba3 was 
likewise enhanced at 60 and 90 min after the addition of MVA, but declined again after 120 min, whereas bcaba4 was constitutively expressed at a low level [19].

In our work, we found that the addition of mevalonic acid cannot lead to an increased production of ABA obviously in B. cinerea TB-3-H8. Therefore, we investigated the expression levels of the four function genes during ABA production in TB-3-H8. The transcript levels of bcabal, 2 and 3 are found to be enhanced at $52 \mathrm{~h}$, then they decrease and peak again at 113 and $137 \mathrm{~h}$, respectively. The expression of bcaba4 appeared to a rapid increase at $89 \mathrm{~h}$, then it decreased and reached maximum expression at $161 \mathrm{~h}$. It was shown that the expression patterns of bcabal-4 have a similar trend over the time course.

\section{Experimental Section}

\subsection{Strains, Plasmids and Culture Conditions}

Escherichia coli strain JM109 was used for the propagation of plasmids. The pMD18-T vector (Takara, Otsu, Japan) was used for cloning PCR fragments. E. coli cells were grown in Luria-Bertani (LB) liquid broth or on LB agar. B. cinerea TB-3-H8 was a mutant strain obtained after UV treatment of a wild strain originally isolated from wheat stem, and leaf. B. cinerea strains were grown on potato dextrose agar (PDA) [27]. For the seeding culture, B. cinerea TB-3-H8 was grown in YP medium (containing $6.0 \mathrm{~g} / \mathrm{L}$ glucose, $10 \mathrm{~g} / \mathrm{L}$ yeast extract, $5.0 \mathrm{~g} / \mathrm{L}$ soluble starch, $1.0 \mathrm{~g} / \mathrm{L}$ sucrose, $1.0 \mathrm{~g} / \mathrm{L}$ $\mathrm{NH}_{4} \mathrm{NO}_{3}$ and $1.0 \mathrm{~g} / \mathrm{L} \mathrm{KH}_{2} \mathrm{PO}_{4}$ ) for $48 \mathrm{~h}$ at $26^{\circ} \mathrm{C}$ and $200 \mathrm{rpm}$. For ABA production, FJ2 fermentation medium (containing $6.0 \mathrm{~g} / \mathrm{L}$ glucose, $10 \mathrm{~g} / \mathrm{L}$ yeast extract, $3.0 \mathrm{~g} / \mathrm{L}$ soluble starch, $1.0 \mathrm{~g} / \mathrm{L}$ soybean meal, $2.0 \mathrm{~g} / \mathrm{L}$ sucrose, $0.5 \mathrm{~g} / \mathrm{L} \mathrm{NH}_{4} \mathrm{NO}_{3}$ and $1.0 \mathrm{~g} / \mathrm{L} \mathrm{KH}_{2} \mathrm{PO}_{4}$ ) and $\mathrm{FB} 2$ feeding medium (containing $2.0 \mathrm{~g} / \mathrm{L}$ glucose, $1.0 \mathrm{~g} / \mathrm{L}$ sucrose, $5.0 \mathrm{~g} / \mathrm{L}$ yeast extract and $0.5 \mathrm{~g} / \mathrm{L}$ soybean meal) was employed. In addition, the two B. cinerea (B05.10 and T4) genomes available in databases were also included in this study.

\subsection{Fed-Batch Fermentation and Determination of $A B A$}

B. cinerea TB-3-H8 cultivated on PDA slants for seven days at $26{ }^{\circ} \mathrm{C}$ were inoculated into $30 \mathrm{~mL}$ fermentation seed medium in 250-mL flasks. After incubation for $48 \mathrm{~h}$ at $26^{\circ} \mathrm{C}$ and $200 \mathrm{rpm}$, cultures were trans-inoculated into a $15 \mathrm{~L}$ fermentation tank with $8 \mathrm{~L}$ fermentation medium by $10 \%$ inoculation $(v / v)$ and grown for 10 days at $30{ }^{\circ} \mathrm{C}$ and $200 \mathrm{rpm}$. The fed-batch fermentation was performed by the continuous supply of sterile feeding medium after $60 \mathrm{~h}$. For quantification of ABA, $25 \mathrm{~mL}$ fermentation broth were collected. After centrifuging, the supernatants were analyzed at appropriate dilutions by high performance liquid chromatography (HPLC). ABA $(98 \%, w / w$, Lomon Bio Technology Co., Ltd., Sichuan, China) was used to make the standard curve for quantitative determination.

\subsection{DNA Manipulation and PCR Amplification}

Total DNA from B. cinerea TB-3-H8 used in this work was isolated as described previously by Möller [39]. One $\mu \mathrm{L}$ of the DNA was added to the PCR mix containing $5 \mu \mathrm{L}$ of supplied PCR buffer, $0.2 \mathrm{mM}$ deoxynucleoside triphosphates (dNTPs), $0.2 \mathrm{mM}$ each oligonucleotide primer, $2 \mathrm{U}$ of KOD-Plus NEO (KOYOTO, Osaka, Janpan) and water in a final volume of $50 \mu \mathrm{L}$. PCR amplification was performed using a DNA thermal cycler (Mastercycler; Eppendorf) for 30 cycles with the general 
program $\left(94{ }^{\circ} \mathrm{C}\right.$ for $30 \mathrm{~s}, 30 \mathrm{~s}$ at the suitable annealing temperature of the primers used and $72{ }^{\circ} \mathrm{C}$ for 1 min per $\mathrm{kb}$ of DNA to be amplified). DNA was separated on a $1 \%$ agarose gel in TAE buffer (40 mM Tris-acetate-1 mM EDTA; pH 8.0) and visualized after ethidium bromide staining under UV light conditions. PCR products were purified from an agarose gel by the use of a QIAquick gel extraction kit (Tiangen Biotech. Ltd., Beijing, China).

\subsection{DNA Sequencing}

Total DNA from $B$. cinerea TB-3-H8 was used as DNA templates for sequencing by a polymerase chain reaction (PCR) strategy. Sequencing was performed to identify open reading frames (ORFs) and intergenic regions in the gene cluster involved in ABA formation. Specific primer pairs were made based on the genome of $B$. cinerea $\mathrm{B} 05.10$. The resulting PCR products were cloned to pMD18-T vector (Takara, Japan) and sequenced. All primers used in this study are outlined in Figure 1.

\subsection{RNA Extraction}

Mycelia were collected at different time points, frozen immediately in liquid nitrogen and ground into powder with a pestle and mortar. RNA isolation was carried out with TRIzol ${ }^{\mathrm{TM}}$ (Invitrogen, Carlsbad, CA, USA) following the procedures recommended by the manufacturer. Contaminating DNA was removed by digestion with DNase I (Takara, Japan) and verified by PCR analysis with the RNA as the template. The concentration and integrity of the RNA isolations were determined by both spectrophotometry and agarose gel electrophoresis.

\subsection{Coding Sequence and Intron Identification by Reverse Transcriptase (RT)-PCR}

The first strand of cDNA was synthesized from $20 \mu \mathrm{g}$ DNaseI-treated RNA with the PrimeScript ${ }^{\mathrm{TM}}$ RT reagent Kit (Takara, Japan) and used as the template in PCR. The PCR amplification was carried out as described above [28]. The resulting cDNA fragments were sequenced directly. Intervening sequences (introns) were located by comparison of the genomic DNA to cDNA sequences. Sequence analysis and amino acid prediction/translation have been performed using ClustalW program [40]. All primers used in this study are outlined in Table 2.

Table 2. Primer pairs used for cDNA cloning.

\begin{tabular}{ccc}
\hline Genes & Forward Primers (5'-3') & Reverse Primers (5'-3') \\
\hline bcababal & 5'-ATGTCTAATTCTATATTGAAC-3' & 5'-CTATTTGTATTCTGTTCCC-3' \\
$b c a b a b a 2$ & 5'-ATGCTGCTTAGCATTAAAGA-3' & 5'-CTATCTAGGAACCTCTTTTA-3' \\
bcababa3 & 5'-ATGCAGCAAGTTATTACTCA-3' & 5'-CTAGGTACTTTCTCCACGAT-3' \\
bcababa4 & 5'-ATGTCCTCTCAACCATTCAC-3' & 5'-CTAACATCTCCATCCGCCAT-3' \\
\hline
\end{tabular}

\subsection{Sequence Analysis}

The unmasked B. cinerea TB-3-H8 genomic sequences of bcabal-4 gene clusters were compared with the corresponding B05.10 genomic sequences by using BLAST on the web server. Promoters were detected with Promoter 2.0 Prediction Serve [41]. Dot plot analysis was done with the program 
PipMaker [42]. Secondary structures of potential gene products were analyzed with the Bioannotator program from Vector NTI software. For detailed comparisons, local and global pairwise alignments were calculated with the program, AlignX, from Vector NTI software.

\subsection{Analysis of Gene Expression Profiling by SYBR Green Real-Time PCR Assays}

Gene expression profile analysis was carried out by real time-PCR [43-46]. Amplification was carried out in a Bio-Rad Chromo 4 Real-Time PCR Detection System (Bio-Rad, Hercules, CA, USA) with the Tiangen SYBR Green RealMasterMix (Tiangen Biotech. Ltd., Beijing, China). The 18S rRNA gene was used to correct for sample-to-sample variation in the amount of RNA. The relative mRNA amounts were calculated by the $2^{-\Delta \Delta C t}$ method from the mean of three independent determinations of the threshold cycle, as described [36]. All primers used in this study are outlined in Table 3.

Table 3. Sequences of oligonucleotide primers designed for qPCR.

\begin{tabular}{cccc}
\hline Genes & Forward Primers (5'-3') & Reverse Primers (5'-3') & $\begin{array}{c}\text { Product } \\
\text { Size (bp) }\end{array}$ \\
\hline bcabal & 5'-GCCCAAAGCCTACTGATAAA-3' & 5'-TGTCGAATGAATGACCCAAG-3' & 124 \\
$b c a b a 2$ & 5'-CTTATTACTTCCCGTTTACTC-3' & 5'-CTTATTACTTCCCGTTTACTC-3' & 101 \\
$b c a b a 3$ & 5'-CAAGGAACTCAGCAAGCCC-3' & 5'-AGTCGATGCCAACAAAAGG-3' & 102 \\
bcaba4 & 5'-CTTGGACGAGTGGGAGTT-3' & 5'-GCCGTTGTTAGCCATTAC-3' & 91 \\
$18 S$ r $R$ A & 5'-GAAACTCACCAGGTCCAGA-3' & 5'-CAAATCACTCCACCAACTAAG-3' & 104 \\
\hline
\end{tabular}

\section{Conclusions}

In summary, this work describes the existence of $B$. cinerea strain TB-3-H8 with the capability to produce ABA. The gene cluster of this pathway has been characterized and was shown to possess the same organization with the other strains, B05.10 and T4. The differences between strains, such as several point mutations in the coding sequence, the presence or absence of an inactivated LTR element, or of two inactivated LTR elements, and the gene expression profiles, reflect different steps in the evolution of $B$. cinerea strains and give us clues to the molecular mechanism of ABA production.

\section{Acknowledgments}

The authors thank the support from the Keynote Program of the Chinese Academy of Sciences (KSZD-EW-Z-021-3-1) and the Open Research Fund of Key Laboratory of Environmental and Applied Microbiology, Chengdu Institute of Biology, Chinese Academy of Sciences (KLCAS-2013-02; KLCAS-2012-01). The project was also supported by from West Light Foundation of the Chinese Academy of Science (Y1C5031).

\section{Author Contributions}

Gong Tao and Shu Dan co-performed all the sequence and transcriptional analyses, co-processed the samples and co-analyzed the database, and drafted the manuscript. Yang Jie helped with the fermentation of B.cinerea strains. Ding Zhong-Tao helped with the analyses of the database. Tan Hong designed the study and helped with the draft of the manuscript. 


\section{Conflicts of Interest}

The authors declare no conflict of interest.

\section{References}

1. Rabbani, M.A.; Maruyama, K.; Abe, H.; Khan, M.A.; Katsura, K.; Ito, Y.; Yoshiwara, K.; Seki, M.; Shinozaki, K.; Yamaguchi-Shinozaki, K. Monitoring expression profiles of rice genes under cold, drought, and high-salinity stresses and abscisic acid application using cDNA microarray and RNA gel-blot analyses. Plant Physiol. 2003, 133, 1755-1767.

2. Tsavkelova, E.; Klimova, S.Y.; Cherdyntseva, T.; Netrusov, A. Microbial producers of plant growth stimulators and their practical use: A review. Appl. Biochem. Microbiol. 2006, 42, 117-126.

3. Secchi, F.; Perrone, I.; Chitarra, W.; Zwieniecka, A.K.; Lovisolo, C.; Zwieniecki, M.A. The dynamics of embolism refilling in abscisic acid (ABA)-deficient tomato plants. Int. J. Mol. Sci. 2012, 14, 359-377.

4. Dorffling, K.; Petersen, W.; Sprecher, E.; Urbasch, I.; Hanssen, H. Abscisic acid in phytopathogenic fungi of the genera Botrytis, Ceratocystis, Fusarium, and Rhizoctoma. Zeitschrift fur Naturforschung. Sect. C Biosci. 1984, 39, 683-684.

5. Marumo, S.; Katayama, M.; Komori, E.; Ozaki, Y.; Natsume, M.; Kondo, S. Microbial production of abscisic acid by Botrytis cinerea. Agric. Biol. Chem. 1982. 46, 1967-1968.

6. Zhou, J.; Wu, K.; Lei, B.; Yang, J.; Tan, H. Isolation method and biological activity of metabolites from Botrytis cinerea. Chin. J. Appl. Environ. Biol. 2001, 8, 532-534.

7. Wang, H.; Niu, X.; Zhang, J.; Dong, J.; Shang, H. Isolation and identification of abscisic acid from BC4 isolate of Botrytis cinerea. J. Northwest. Sci.-Tech. Univ. Agric. For. 2003, 32, 34-36.

8. Zhang, H.; Liu, J.; He W. Screening of abscisic acid producing fungi and optimization of its fermentation conditions. Ind. Microbiol. 2008, 1, 49-52.

9. Hirai, N.; Yoshida, R.; Todoroki, Y.; Ohigashi, H. Biosynthesis of abscisic acid by the non-mevalonate pathway in plants, and by the mevalonate pathway in fungi. Biosci. Biotechnol. Bbiochem. 2000, 64, $1448-1458$.

10. Nambara, E.; Marion-Poll, A. Abscisic acid biosynthesis and catabolism. Annu. Rev. Plant Biol. 2005, 56, 165-185.

11. Oritani, T.; Kiyota, H. Biosynthesis and metabolism of abscisic acid and related compounds. Nat. Prod. Rep. 2003, 20, 414-425.

12. Srivastava, L.M. Plant Growth and Development: Hormones and Environment; Academic Press: London, UK, 2002; pp. 217-231.

13. Inomata, M.; Hirai, N.; Yoshida, R.; Ohigashi, H. The biosynthetic pathway to abscisic acid via ionylideneethane in the fungu Botrytis cinerea. Phytochemistry 2004, 65, 2667-2678.

14. Yamamoto, H.; Inomata, M.; Tsuchiya, S.; Nakamura, M.; Oritani, T. Metabolism of chiral ionylideneacetic acids on the abscisic acid biosynthetic pathway in Cercospora. Biosci. Biotechnol. Bbiochem. 2000, 64, 2644-2650.

15. Bennett, R.D.; Norman, S.M.; Maier, V. Intermediate steps in the biosynthesis of abscisic acid from farnesyl pyrophosphate in Cercospora rosicola. Phytochemistry 1990, 29, 3473-3477. 
16. Inomata, M.; Hirai, N.; Yoshida, R.; Ohigashi, H. Biosynthesis of abscisic acid by the direct pathway via ionylideneethane in a fungus, Cercospora cruenta. Biosci. Biotechnol. Biochem. 2004, $68,2571-2580$.

17. Kato, T.; Oritani, T.; Yamashita, K. Metabolism of $(2 Z, 4 E)-\gamma$-ionylideneethanol and $(2 Z, 4 E)-\gamma$-ionylideneacetic acid in Cercospora cruenta. Agric. Biol. Chem. 1987, 51, 2695-2699.

18. Okamoto, M.; Hirai, N.; Koshimizu, K. Biosynthesis of abscisic acid from $\alpha$-ionylideneethanol in Cercospora pini-densiflorae. Phytochemistry 1988, 27, 3465-3469.

19. Siewers, V.; Kokkelink, L.; Smedsgaard, J.; Tudzynski, P. Identification of an abscisic acid gene cluster in the grey mold Botrytis cinerea. Appl. Environ. Microbiol. 2006, 72, 4619-4626.

20. Siewers, V.; Smedsgaard, J.; Tudzynski, P. The P450 monooxygenase BcABA1 is essential for abscisic acid biosynthesis in Botrytis cinerea. Appl. Environ. Microbiol. 2004, 70, 3868-3876.

21. Law, Y.-S.; Gudimella, R.; Song, B.-K.; Ratnam, W.; Harikrishna, J.A. Molecular characterization and comparative sequence analysis of defense-related gene, oryza rufipogon receptor-like protein kinase 1. Int. J. Mol. Sci. 2012, 13, 9343-9362.

22. Botrytis cinerea B05.10 genome. Available online: http://www.broadinstitute.org/annotation/genome/ botrytis_cinerea/GenomeDescriptions.html\#BC1 (accessed on 16 August 2014).

23. Botrytis cinerea T4genome. Available online: http://www.broadinstitute.org/annotation/genome/ botrytis_cinerea/GenomeDescriptions.html\#Botcin_T4_vankan (accessed on 16 August 2014).

24. Botrytis cinerea T4genome. Available online: https://urgi.versailles.inra.fr/Species/Botrytis (accessed on 16 August 2014).

25. Amselem, J.; Cuomo, C.A.; van Kan, J.A.; Viaud, M.; Benito, E.P.; Couloux, A.; Coutinho, P.M.; de Vries, R.P.; Dyer, P.S.; Fillinger, S. Genomic analysis of the necrotrophic fungal pathogens Sclerotinia sclerotiorum and Botrytis cinerea. PLoS Genet. 2011, 7, e1002230.

26. Campbell, M.A.; Staats, M.; van Kan, J.A.; Rokas, A.; Slot, J.C. Repeated loss of an anciently horizontally transferred gene cluster in Botrytis. Mycologia 2013, 105, 1126-1134.

27. Tan, H.; Gong, G.; Li, Z.; Peng, S.; Lei, B.; Liu, D.; Ding, L. High-yield ABA producing strain obtained by UV irradiation of protoplasts. Chin. J. Appl. Envrion. Biol. 1998, 3, 281-285.

28. Gong, T.; Shu, D.; Zhao, M.; Zhong, J.; Deng, H.Y.; Tan, H. Isolation of genes related to abscisic acid production in Botrytis cinerea TB-3-H8 by cDNA-AFLP. J. Basic Microbiol. 2014, 54, $204-214$.

29. Conserved Domains and Protein Classification. Available online: http://www.ncbi.nlm.nih.gov/cdd/ (accessed on 18 October 2013).

30. Spiering, M.J.; Moon, C.D.; Wilkinson, H.H.; Schardl, C.L. Gene clusters for insecticidal loline alkaloids in the grass-endophytic fungus Neotyphodium uncinatum. Genetics 2005, 169, 1403-1414.

31. Zhao, M.; Zhou, J.Y.; Li, Z.D.; Song, W.W.; Gong, T.; Tan, H. Boty-like retrotransposons in the filamentous fungus Botrytis cinerea contain the additional antisense gene brtn. Virology 2011, 417, 248-252.

32. Choquer, M.; Fournier, E.; Kunz, C.; Levis, C.; Pradier, J.M.; Simon, A.; Viaud, M. Botrytis cinerea virulence factors: New insights into a necrotrophic and polyphageous pathogen. FEMS Microbiol. Lett. 2007, 277, 1-10.

33. Tudzynski, B.; Sharon, A. Biosynthesis, biological role and application of fungal phytohormones. The Mycota 2002, 10, 183-211.

34. Tokugawa, N.; Shirai, M.; Yonehara, T. Production of Nature-Type Abscisic Acid. JP6247927A, 1994. 
35. Shu, D.; Xiao, L. Chengdu Institute of Biology, Chinese Academy of Sciences, Chengdu, China. Unpublished work, 2013.

36. Malonek, S.; Rojas, M.; Hedden, P.; Gaskin, P.; Hopkins, P.; Tudzynski, B. Functional characterization of two cytochrome P450 monooxygenase genes, P450-1 and P450-4, of the gibberellic acid gene cluster in Fusarium proliferatum (Gibberella fujikuroi MP-D). Appl. Environ. Microbiol. 2005, 71, 1462-1472.

37. Shu, D.; Zhong, J. Chengdu Institute of Biology, Chinese Academy of Sciences, Chengdu, China. Unpublished work, 2013.

38. Ladero, V.; Rattray, F.P.; Mayo, B.; Martín, M.C.; Fernández, M.; Alvarez, M.A. Sequencing and transcriptional analysis of the biosynthesis gene cluster of putrescine-producing Lactococcus lactis. Appl. Environ. Microbiol. 2011, 77, 6409-6418.

39. Möller, E.; Bahnweg, G.; Sandermann, H.; Geiger, H. A simple and efficient protocol for isolation of high molecular weight DNA from filamentous fungi, fruit bodies, and infected plant tissues. Nucleic Acids Res. 1992, 20, 6115.

40. Thompson, J.D.; Higgins, D.G.; Gibson, T.J. ClustalW: Improving the sensitivity of progressive multiple sequence alignment through sequence weighting, position-specific gap penalties and weight matrix choice. Nucleic Acids Res. 1994, 22, 4673-4680.

41. Knudsen, S. Promoter2. 0: For the recognition of PolII promoter sequences. Bioinformatics 1999, 15, 356-361.

42. Schwartz, S.; Zhang, Z.; Frazer, K.A.; Smit, A.; Riemer, C.; Bouck, J.; Gibbs, R.; Hardison, R.; Miller, W. PipMaker-a web server for aligning two genomic DNA sequences. Genome Res. 2000, 10, 577-586.

43. Suarez, M.B.; Walsh, K.; Boonham, N.; O’Neill, T.; Pearson, S.; Barker, I. Development of real-time PCR (TaqMan) assays for the detection and quantification of Botrytis cinerea in planta. Plant Physiol. Biochem. 2005, 43, 890-899.

44. Zhao, W.; Huang, Z.; Chen, Y.; Zhang, Y.; Rong, G.; Mu, C.; Xu, Q.; Chen, G. Molecular cloning and functional analysis of the duck TLR4 Gene. Int. J. Mol. Sci. 2013, 14, 18615-18628.

45. Wan, L.; Ma, J.; Xu, G.; Wang, D.; Wang, N. Molecular cloning, structural analysis and tissue expression of protein phosphatase 3 catalytic subunit alpha isoform (PPP3CA) gene in Tianfu goat muscle. Int. J. Mol. Sci. 2014, 15, 2346-2358.

46. Livak, K.J.; Schmittgen, T.D. Analysis of relative gene expression data using real-time quantitative PCR and the $2^{-\Delta \Delta C t}$ method. Methods 2001, 25, 402-408.

(C) 2014 by the authors; licensee MDPI, Basel, Switzerland. This article is an open access article distributed under the terms and conditions of the Creative Commons Attribution license (http://creativecommons.org/licenses/by/4.0/). 